\title{
Original
}

Shapiro, M.; Shukla, J.; Brunet, G.; Nobre, C.; Beland, M.; Dole, R.;

Trenberth, K.; Anthes, R.; Asrar, G.; Barrie, L.; Bougeault, P.; Brasseur, G.P.; Burridge, D.; Busalacchi, A.; Caughey, J.; Chen, D.; Church, J.; Enomoto, T.; Hoskins, B.; Hov, O.; Laing, A.; Le Treut, H.; Marotzke, J.; McBean, G.; Meehl, G.; Miller, M.; Mills, B.; Mitchell, J.; Moncrieff, M.; Nakazawa, T.; Olafsson, H.; Palmer, T.; Persons, D.; Rogers, D.; Simmons, A.; Troccoli, A.; Toth, Z.; Uccellini, L.; Velden, C.; Wallace, J.M.:

An Earth-System Prediction Initiative for the Twenty-First Century

In: Bulletin of the American Meteorological Society (2010) AMS

DOI: 10.1175/2010BAMS2944.1 


\section{AN EARTH-SYSTEM \\ PREDICTION INITIATIVE FOR THE TWENTY-FIRST CENTURY}

by Melvyn Shapiro, Jagadish Shukla, Gilbert Brunet, Carlos Nobre, Michel Béland, Randall Dole, Kevin Trenberth, Richard Anthes, Ghassem Asrar, leonard Barrie, Philippe Bougeault, Guy Brasseur, David Burridge, Antonio Busalacchi, Jim Caughey, Deliang Chen, John Church, Takeshi Enomoto, Brian Hoskins, Øystein Hov, Arlene Laing, Hervé Le Treut, Jochem Marotzke, Gordon McBean, Gerald Meehl, Martin Miller, Brian Mills, John Mitchell, Mitchell Moncrieff, Tetsuo Nakazawa, Haraldur Olafsson, Tim Palmer,

David Parsons, David Rogers, Adrian Simmons, Alberto Troccoli, Zoltan Toth, Louis Uccellini, Christopher Velden, and John M. Wallace

\section{An international interdisciplinary initiative to accelerate advances in knowledge, prediction,} use, and value of weather, climate, and Earth system information.

W e stand at the threshold of accelerating major advances in observations, analysis, and prediction of high-impact weather and climate. Such advances would protect lives and inform crucial environmental decisions affecting this and future generations. The development of new integrated approaches to Earth system science will be essential to realizing these advances.

Currently, 12-48-h forecasts, on spatial scales of a few kilometers, provide timely and accurate warnings of flooding rainstorms, river flows, tornadoes, storm surges, hurricane track and landfall, and air-quality emergencies. Global 5-day forecasts have accuracy comparable to 2-day forecasts of $25 \mathrm{yr}$ ago (Fig. 1). There is increasing evidence of predictability of some extreme weather events $7-10$ days in advance (Hamill et al. 2006). Seasonal forecasts provide useful information on El Niño and La Niña and their likely influences on regional weather, such as shifts in the North Pacific storm track. Assessments and projections of global temperature, sea level, arctic sea ice, and precipitation over decades to centuries contribute to the scientific underpinning for international action to reduce greenhouse gas and aerosol emissions (Meehl et al. 2007). Risk models have become increasingly important in exposing potential vulnerabilities and evaluating the outcomes of decisions. These accomplishments have been made possible through investments in weather and climate research and technology, which have produced some of the most significant scientific achievements of the twentieth century.

Although these advances are impressive, increasing vulnerabilities, along with the threat of humaninduced climate change, they are driving urgent needs for further improvements in weather and climate information. This information is required to support a wide range of decisions, such as protection of life and property from extreme weather events and policy decisions and infrastructure planning related to climate change, including the co-benefits and trade-offs of air pollution and climate mitigation (Jacob and Winner 2009) and those related to the coupling of the reactive nitrogen cycle with food production, population growth, climate, water 
availability and quality, and biodiversity (Erisman et al. 2008). Such improvements will require significant advances in observations, prediction, and understanding of the complex interactions between the physical-biological-chemical Earth system ${ }^{1}$ and global societies (NRC 2007, 2008).

Recognizing this challenge, delegates and scientists associated with the (refer to the appendix for acronym expansions) WMO, WCRP, WWRP, GAW, and IGBP proposed the Earth-System Prediction Initiative (EPI) at the 2007 GEO Summit in Cape Town, South Africa (Shapiro et al. 2007). A major objective of EPI is to develop and foster collaborative research priorities between these international programs.

The 2008 World Modeling Summit for Climate Prediction at the ECMWF in Reading, United
Kingdom, recommended the creation of advanced climate research and computing facilities (Shukla et al. 2009). The WCC3, (www.wmo.int/wcc3/page_en.php) in Geneva, Switzerland, in 2009, proposed a Global Framework for Climate Services to strengthen production, delivery, and application of science-based climate prediction and services. More recently, the ESSP, involving four global environmental change research programs under the ICSU (i.e., Diversitas, IGBP, the IHDP, and WCRP) developed a closely related strategic vision for its program (Leemans et al. 2009). ICSU, in cooperation with the ISSC, is spearheading a process on Earth system visioning (www.icsu-visioning. org/) to develop a new vision and strategic framework for Earth system research (Walter et al. 2009). The ICSU study (www.icsu.org/2_resourcecentre/

\footnotetext{
${ }^{1}$ The Earth system encompasses the atmosphere and its chemical composition, the oceans, land/sea ice and other cryosphere components as well as the land surface, including surface hydrology and wetlands, lakes, and human activities. On short time scales, it includes phenomena that result from the interaction between one or more components, such as ocean waves and storm surges. On longer time scales (e.g., climate), the terrestrial and ocean ecosystems, including the carbon and nitrogen cycles and slowly varying cryosphere components (e.g., the large continental ice sheets and permafrost), are also part of the Earth system.
}

AFFILIATIONS: SHAPIRO- National Center for Atmospheric Research,* Boulder, Colorado, and Geophysical Institute, University of Bergen, Bergen, Norway; SHUKLA-George Mason University, Fairfax, Virginia, and Institute of Global Environment and Society, Calverton, Maryland; BRUNET AND BÉLAND-Atmospheric Science and Technology Directorate, Environment Canada, Montreal, Quebec, Canada; Nobre-Center for Earth System Science, National Institute for Space Research, São José dos Campos, Brazil; DOLE AND TOTH—NOAA/Earth System Research Laboratory, Boulder, Colorado; Trenberth, Laing, Meehl, ANd MoncriefFNational Center for Atmospheric Research, Boulder, Colorado; ANTHES-University Corporation for Atmospheric Research, Boulder, Colorado; AsRaR-World Climate Research Programme, World Meteorological Organization, Geneva, Switzerland; BARRIE-Atmospheric Research and Environment Programme, World Meteorological Organization, Geneva, Switzerland; Bougeault-Météo France, Toulouse, France; BrasseurClimate Service Center, Hamburg, Germany; BuRRIDGE AND CAUGHEY - THORPEX, World Weather Research Programme, World Meteorological Organization, Geneva, Switzerland; BUSALACCHI-Earth System Science Interdisciplinary Center, University of Maryland, College Park, College Park, Maryland; CHEN-Department of Earth Sciences, University of Gothenburg, Gothenburg, Sweden, and International Council for Science, Paris, France; $\mathrm{CHURCH}$ - Centre for Australian Weather and Climate Research, the Bureau of Meteorology and the Commonwealth Scientific and Industrial Research Organisation, Hobart, Tasmania, Australia; Еломото-Earth Simulator Center, Japan Agency for Marine-Earth Science and Technology, Yokohama, Japan; HoskINS-Department of Meteorology, University of Reading, Reading, and Grantham Institute, Imperial College London, London, United Kingdom; Hov-Norwegian Meteorological
Institute, Oslo, Norway; Le TReUT—Laboratoire de Météorologie Dynamique, Palaiseau, France; MAROTZKE-Max Planck Institute for Meteorology, Hamburg, Germany; McBeAN—Institute for Catastrophic Loss Reduction, University of Western Ontario, London, Ontario, Canada; Miller ANd Simmons-European Centre for Medium-Range Weather Forecasts, Reading, United Kingdom; MıLls-Adaptation and Impacts Research Division, Environment Canada, Waterloo, Ontario, Canada; MitChelL-Met Office, Exeter, United Kingdom; NAKAZAWA-Meteorological Research Institute, Tsukuba, Japan; OLAfSSON-University of Iceland, Reykjavik, Iceland, and University of Bergen, Bergen, Norway; PALMEREuropean Centre for Medium-Range Weather Forecasts, Reading, and University of Oxford, Oxford, United Kingdom; PARSONSWorld Weather Research Programme, World Meteorological Organization, Geneva, Switzerland; Rogers-Health and Climate Foundation, Washington, D.C.; TROCCOLI-Environmental Systems Science Centre, University of Reading, Reading, United Kingdom; UCCELLINI-NOAA/NCEP Environmental Modeling Center, Camp Springs, Maryland; VeLDEN-CIMSS, University of Wisconsin-Madison, Madison, Wisconsin; WaLLACE-Department of Meteorology, University of Washington, Seattle, Washington *NCAR is sponsored by the National Science Foundation CORRESPONDING AUTHOR: M. A. Shapiro, National Center for Atmospheric Research, P.O. Box 3000, Boulder, CO 80307-3000 E-mail: mshapiro@ucar.edu

The abstract for this article can be found in this issue, following the table of contents.

DOI:10.1175/2010BAMS2944.1

In final form 4 March 2010

(c) 2010 American Meteorological Society 
ICSU_Belmont_report/ index.html) addresses the international research capability required to respond to the challenge of delivering knowledge to support human action and adaptation to regional environmental change (ICSU, 2010).

The EPI is as challenging as the International Space Station, Genome Project, and Hubble Telescope. It will enable revolutionary advances in Earth system prediction, including capabilities for early warning of weather and climate extremes, providing benefits that far exceed costs. To achieve its objectives, EPI can and must motivate the scientific community, especially young scientists, and communicate to the world its multigenerational benefits. It will draw upon coordination between international programs for Earth system observations, prediction, and warning, such as the WCRP, WWRP, GCOS, and hence contribute to GEO and the GEOSS. It will link with international organizations, such as the ICSU, IOC, UNEP, WMO, and WHO.

This article introduces this initiative and its rationale. Companion papers (Brunet et al. 2010; Nobre et al. 2010; Shukla et al. 2010) discuss key elements of EPI from various research and institutional perspectives.

AN URGENT NEED. Hurricane Katrina; the deadly 2003 European heat wave; the multidecadal drought south of the Sahara; the unprecedented wildfires in Australia in early 2009; and the extended period of extreme snow storms and arctic cold-air outbreaks over Europe, Asia, and North America in December 2009-January 2010 confirm the vulnerability of modern society and the environment to adverse weather and climate. In fact, $75 \%$ of natural disasters are triggered by extreme weather and climate phenomena (see online at www.unisdr. org/eng/media-room/facts-sheets/2008-disastersin-numbers-ISDR-CRED.pdf). Vulnerability to weather extremes is projected to increase in coming decades (Karl et al. 2008), intensifying the urgency for advancing mitigation and adaptation capabilities.
Countering this vulnerability with effective mitigation and adaptation requires accurate prediction at global, regional, and local scales.

Earth observation and prediction systems must address the needs of environmentally vulnerable sectors and resources, including energy, water, human health, transportation, agriculture, fisheries, leisure, ecosystems, biodiversity, and national security. These predictions must be probabilistic, providing quantitative estimates of the likelihood of occurrence and severity of different outcomes, including potentially catastrophic extremes. On longer time scales, addressing the uncertainty of climate change predictions and scenarios will be essential to formulating rational and cost-effective mitigation policies for human-induced climate change. This requires improved representations of key processes in Earth system models, such as effects of chemicals, aerosols, clouds, and other hydrological processes, as well as the biosphere and improved modeling of the cryosphere (sea ice, glaciers, continental ice sheets, permafrost).

Although mitigation of human-caused climate change must be addressed globally, adaptation to changes will occur at regional or local scales. Present global climate models are largely incapable of providing this level of detail. Accurate, probabilistic predictions enable rational decisions that reduce human, economic, and environmental losses and also maximize economic opportunities through the 
selection of optimal trade routes, energy allocation, crop selection, pollution reduction, natural resource management, and other practices. Thus, accelerated progress in prediction and services could be valued in billions of dollars.

If we are to address fundamental challenges that span hours to centuries, then it is essential to move beyond individual disciplinary boundaries toward more comprehensive Earth system predictions that include multifaceted connections between different components of the system. Consider, for example, the regional to global impact of Saharan sand and dust

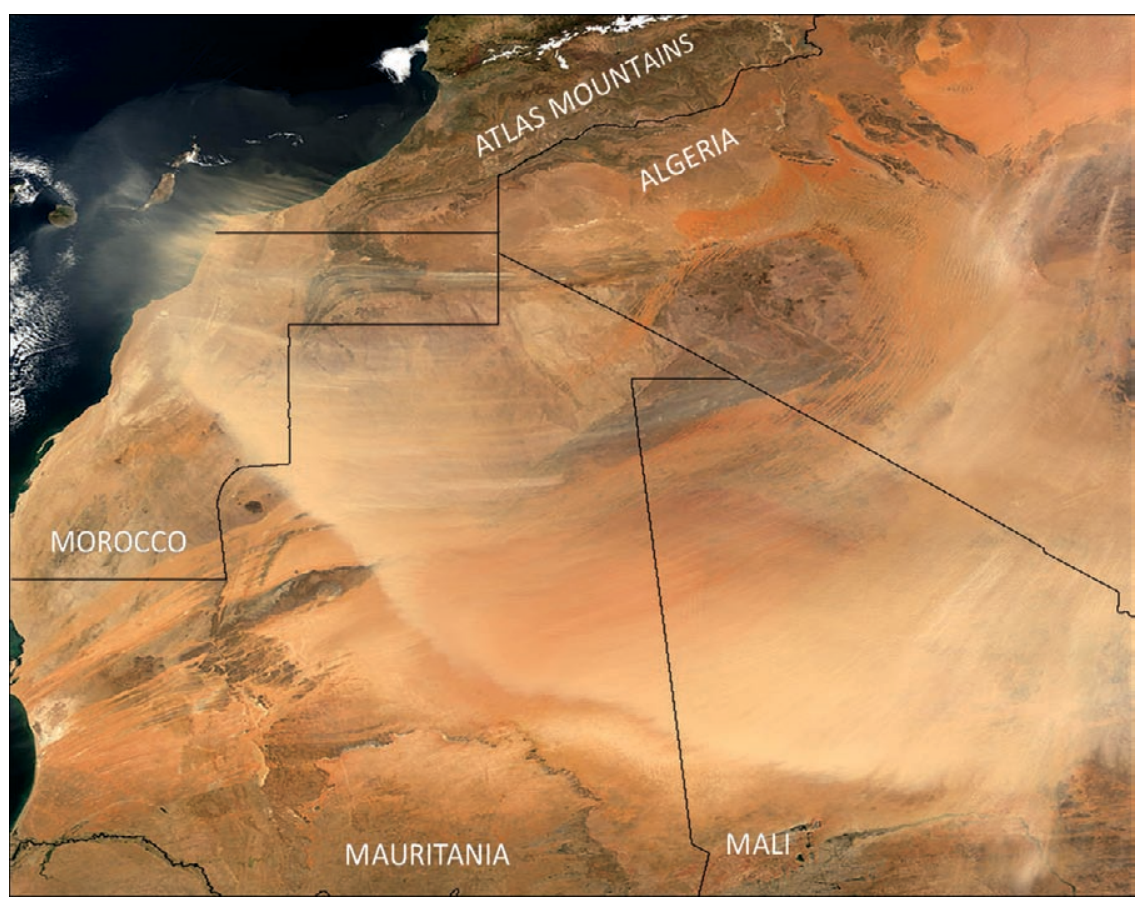

FIG. 2. MODIS satellite view of an extreme Saharan sand and dust event on 6 Mar 2004. storms. Tropospheric aero-

sols from desert storms significantly influence the atmospheric radiative balance, thereby affecting weather and climate (e.g., Kaufman et al. 2002; Li et al. 2004). Variations in seasonal to subseasonal circulations, such as the negative phase of the NAO, deflect the North Atlantic storm track southward into the Mediterranean and North Africa, where individual cyclones trigger massive sand and dust events (Fig. 2). Extratropical cyclone interactions with the mountainous terrain of North Africa locally enhance winds over and around the Atlas, Haggar, Tibesti, and Aïr mountains, increasing the severity of sand and dust storms in their proximity and in distant regions (Todd et al. 2008). In addition, the large-amplitude diurnal temperature cycle over the Sahara modulates the depth of the planetary boundary layer and hence the diurnal concentration of sand and dust (Schepanski et al. 2007).

When Saharan dust is transported over the Atlantic, it can affect the development of tropical cyclones (Evan et al. 2006) and replenish nutrients in the soils of the Amazon, sustaining the rain forest (Nobre et al. 2010). Sand and dust storms supply nutrients to ocean biota, whose concentrations modulate the opacity (solar penetration) of the upper ocean and the oceanic uptake of carbon dioxide, which in turn provide additional feedbacks to the climate system (e.g., Murtugudde et al. 2002; Koren et al. 2006; Ballabrera-Poy et al. 2007). They are also implicated in changing precipitation in the Sahel and West African monsoon regions (Yoshioka et al. 2007) and are a source of aerosols to Europe, impacting visibility, health, and local weather. Meanwhile, Saharan aerosols are under investigation as major contributors to African meningitis epidemics that can place up to 350 million at risk each year (Kelly-Hope and Thompson 2008).

In short, this is not simply a weather, climate, atmosphere, ocean, land surface, chemistry, or biology problem. It is all of these and more. Comprehensive understanding and prediction of such events and their consequences require consideration of the interactions among the different Earth system components, including humankind.

The possibility of "climate surprises" (i.e., unexpected rapid changes outside of current climate model projections) presents another important reason for developing a comprehensive, integrated Earth system approach. Rapid changes may be triggered by relatively fast processes and typically involve feedbacks among different components of the Earth system, such as the physical, biological, and chemical responses to a warming climate that lead to enhanced methane release from melting permafrost (Karl et al. 2008). Also, recent evidence suggests that microbial activity and chemical transformations in sea ice play a potentially important role in regulating uptake of $\mathrm{CO}_{2}$ by arctic seas, providing further evidence for critical 
interactions between land surface or sea ice, through biogeochemical processes, and the physics of climate change, in the overlying lower atmosphere (Rysgaard et al.2009). Reducing the likelihood of future climate surprises requires improved monitoring of Earth system components and their interactions, as well as substantial improvements in Earth system modeling, which means the incorporation of processes not present in current climate models.

We are already moving in this direction. The next IPCC assessment will, for the first time, include global coupled climate models with interactive carbon cycles as standard features. To address challenges such as the potential for rapid changes in sea level beyond current IPCC projections, nextgeneration models will incorporate dynamical ice sheet components to better assess the potential for accelerated ice loss.

A HOLISTIC APPROACH. Accelerating improvements in prediction and services through an inclusive approach to Earth system sciences will require a suite of diagnostic and prediction models integrated over all spatial and temporal scales (Dole 2008; Palmer et al. 2008; Brunet et al. 2010; Hurrell et al. 2009; Meehl et al. 2009). This holistic approach spans highly localized cloud systems to global circulations, linking mesoscale weather life cycles and climate variability and change.

It requires increased integration across the disciplines of physics, mathematics, chemistry, social, and decision sciences. The complexity of the scientific challenges and the need for improved knowledge of diverse impacts will necessitate collaborations between scientists in natural sciences and their colleagues from health, economic, water, agriculture, energy, food, and policy disciplines. This demands intellectual respect and appreciation across the scientific disciplines; collaboration between those who excel in their own fields; joint proposal development guided by multiagency and multinational environmental and socioeconomic priorities; and long-term commitments from scientists, supporting agencies, and stakeholders. Recent examples are the MERIT project (www.hc-foundation.org) and the UCAR Africa Initiative (www.africa.ucar.edu/index. html) on tropical health-climate-weather linkages. The WCRP and WWRP THORPEX sponsored the YOTC; www.ucar.edu/yotc, which has drawn the weather and climate communities together to improve the prediction of the multiscale organization of tropical precipitating cloud systems and their interaction with the global circulation (Fig. 3; see Brunet et al. 2010; Moncrieff et al. 2007). The 2007/08 IPY (www.ipy.org/), sponsored by ICSU and WMO, had a strong emphasis on interdisciplinary research, including marine biology, ocean and atmospheric physics, chemistry, and social sciences. These recent collaborations provide a template for future efforts.

Summoning the necessary resources, technology, and intellect requires coordination and support

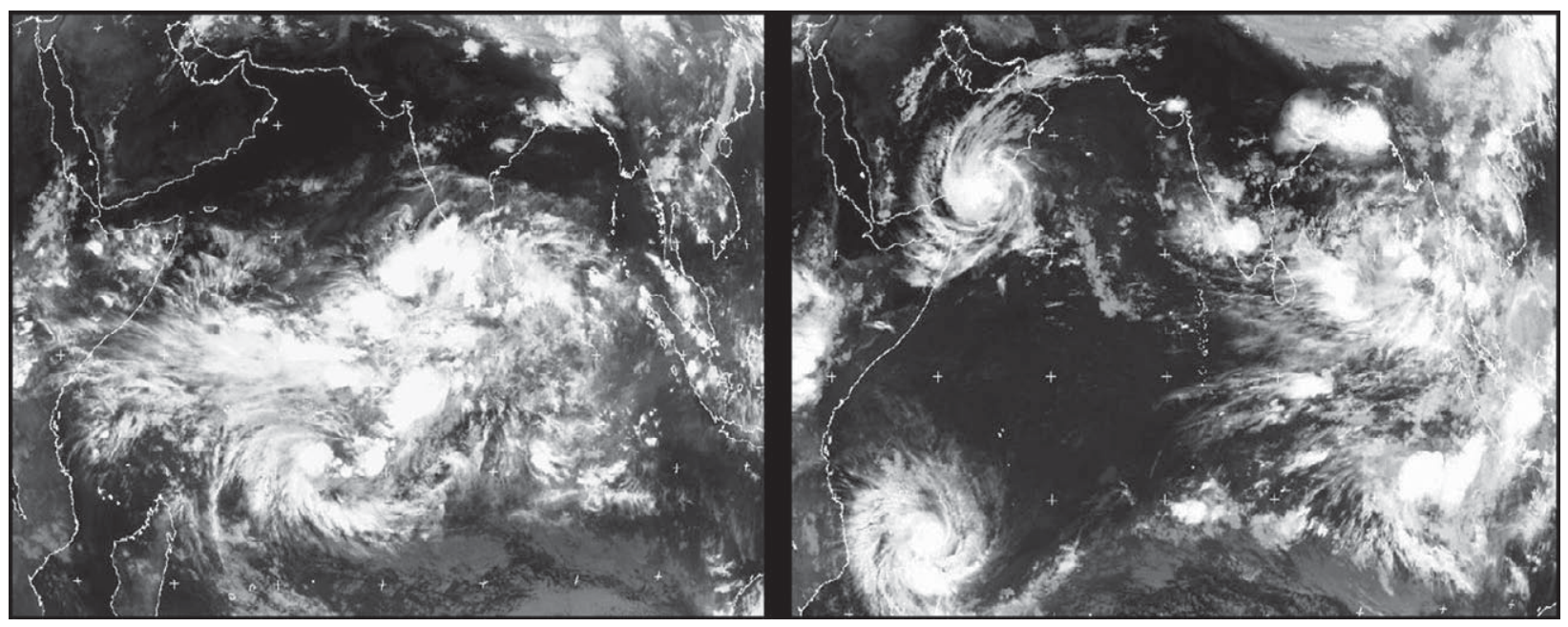

FIG. 3. (left) EUMETSAT IR images of the multiscale organization of tropical convection associated with an MJO over the Indian Ocean on 2 May 2002. (right) By 9 May 2002, the MJO traveled eastward over Indonesia and spawned twin tropical cyclones in its wake, leading to flooding rains and hurricane-force winds over northern Madagascar and heavy precipitation over Yemen. The twin tropical cyclones illustrate high-impact local weather directly associated with large-scale convective organization and equatorial waves (see Moncrieff et al. 2007; Brunet et al. 2010). 
across academic institutions, government research and service agencies, private enterprise, hazard riskreduction and adaptation agencies, and humanitarian organizations. It must bridge regional and national political boundaries. In this context, the GARP (Döös 2004; Uppala et al. 2004) provides a template for the successful outcome of interdisciplinary, multinational engagement to address large, complex problems, such as those proposed in this initiative and companion papers.

CORE ELEMENTS. The elements in the Earth system prediction enterprise are links in a chain, involving access to billions of time-dependent observations that fuel data assimilation systems, that supply the initial conditions for a series of prediction and projection models that in turn provide information for risk reduction and adaptation. The research necessary for the Earth-System Prediction Initiative to accelerate improvements covers each link in that chain.

Prediction models. These models capture the complex interaction among components of the Earth system: They must have sufficient resolution to faithfully represent the multiscale processes of the
Earth system (Figs. 4-6). They will guide mitigation policy and adaptation strategies, including assessing the response and possible unintended consequences of emerging geoengineering alternatives (Fig. 7) for controlling climate variability and change (e.g., Keith 2001; Angel 2006; Crutzen 2006; Latham et al. 2008; Robock 2008). Increasing model resolution and complexity will require substantially greater computing capacity, as discussed in more detail here and in Shukla et al. (2010).

Climate and weather observations. These observations are to monitor the Earth system in every respect. They must achieve reliable detection of global to regional anomalies and support the needs for mitigation and adaptation. This requires improving the established surface and upper-air global observing networks and implementing new surface-based remote sensing and aircraft- and space-based systems to meet the ever increasing observational demands of Earth system monitoring, prediction, and early warning systems. A comprehensive, coordinated observing system is the backbone of the Earth information system (Trenberth 2008). The EPI will provide research for further development, assessment, and use of regional to global observing systems.
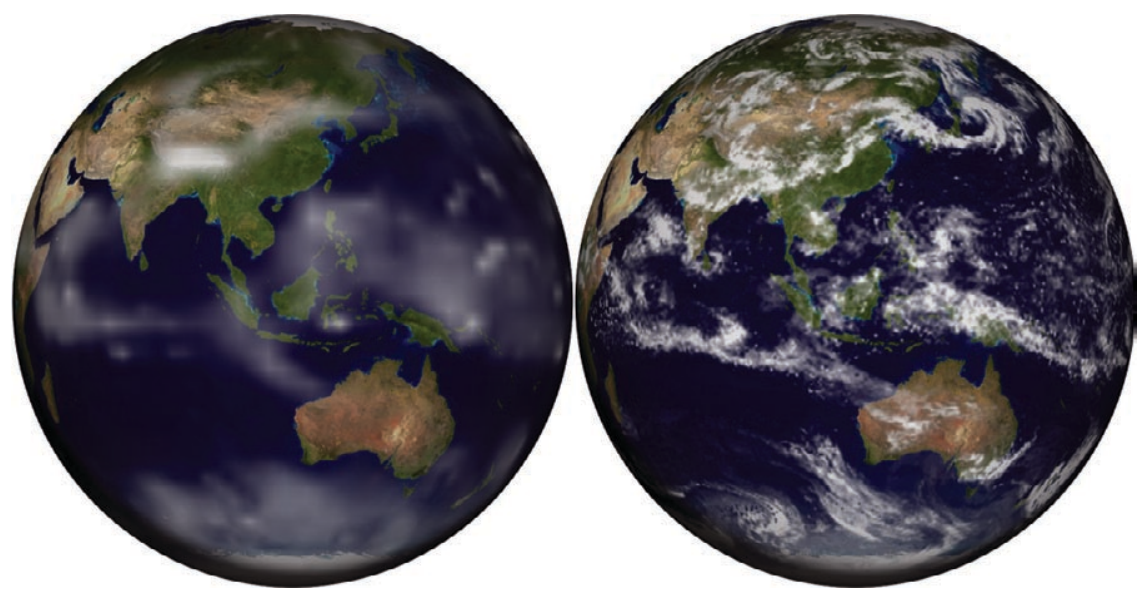

Fig. 4. Atmospheric simulation experiments from I5 Jul 2004 with a general circulation model on the Earth Simulator: (left) global cloud distribution (infrared, shaded) for an experiment with $330-\mathrm{km}$ resolution, representative of some of the coarse-resolution models previously used in climate simulations and global-warming projections (www-pcmdi.IInl.gov/ipcc/model_documentation/ ipcc_model_documentation.php). (right) As in (left), but for a high-resolution simulation $(20-\mathrm{km})$, comparable resolution to the most advanced operational weather forecast models of today (see Fig. 6). The proposed initiative will provide high-resolution climate models that capture the properties of regional high-impact weather events, such as tropical cyclones, heat wave, and sand and dust storms associated within multidecadal climate projections of climate variability and change (courtesy of Shintaro Kawahara, Earth Simulator Center/ JAMSTEC).
High-resolution global and regional data assimilation and analysis systems. These systems are for weather, climate, and Earth system monitoring and prediction and integrate surface- and space-based air, ocean, land, and ice observations across the full suite of Earth system modeling components (Brunet et al. 2010; Nobre et al. 2010). Such systems are a basis for monitoring and assessing past events and change, including their socioeconomic impacts. They provide the initial conditions for new predictions and their verification. GEMS was a step toward a comprehensive data analysis, monitoring, and predicting atmospheric constituents 

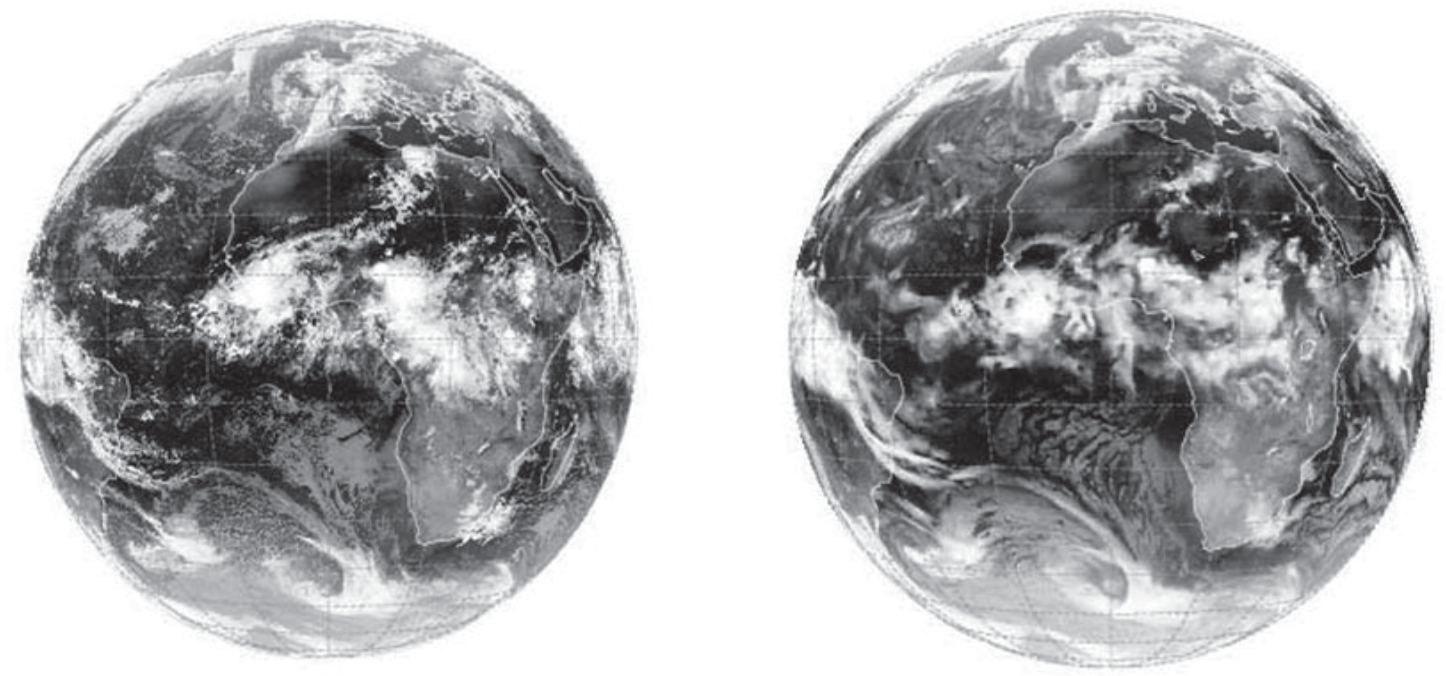

FIG. 5. Global operational 24-h prediction capability at ECMWF at a resolution of TI279 ( 15 km) at 0000 UTC 26 May 2008. (left) EUMETSAT infrared cloud distribution verification, (right) 24-h ECMWF forecast. This example illustrates the remarkable ability of present-day data assimilation and operational NWP to predict the full spectrum of planetary to mesoscale circulations and their interactions (courtesy of Peter Bechtold, ECMWF).

$4 \mathrm{~km}$ WRF, $62 \mathrm{~h}$ forecast Mobile, AL Radar
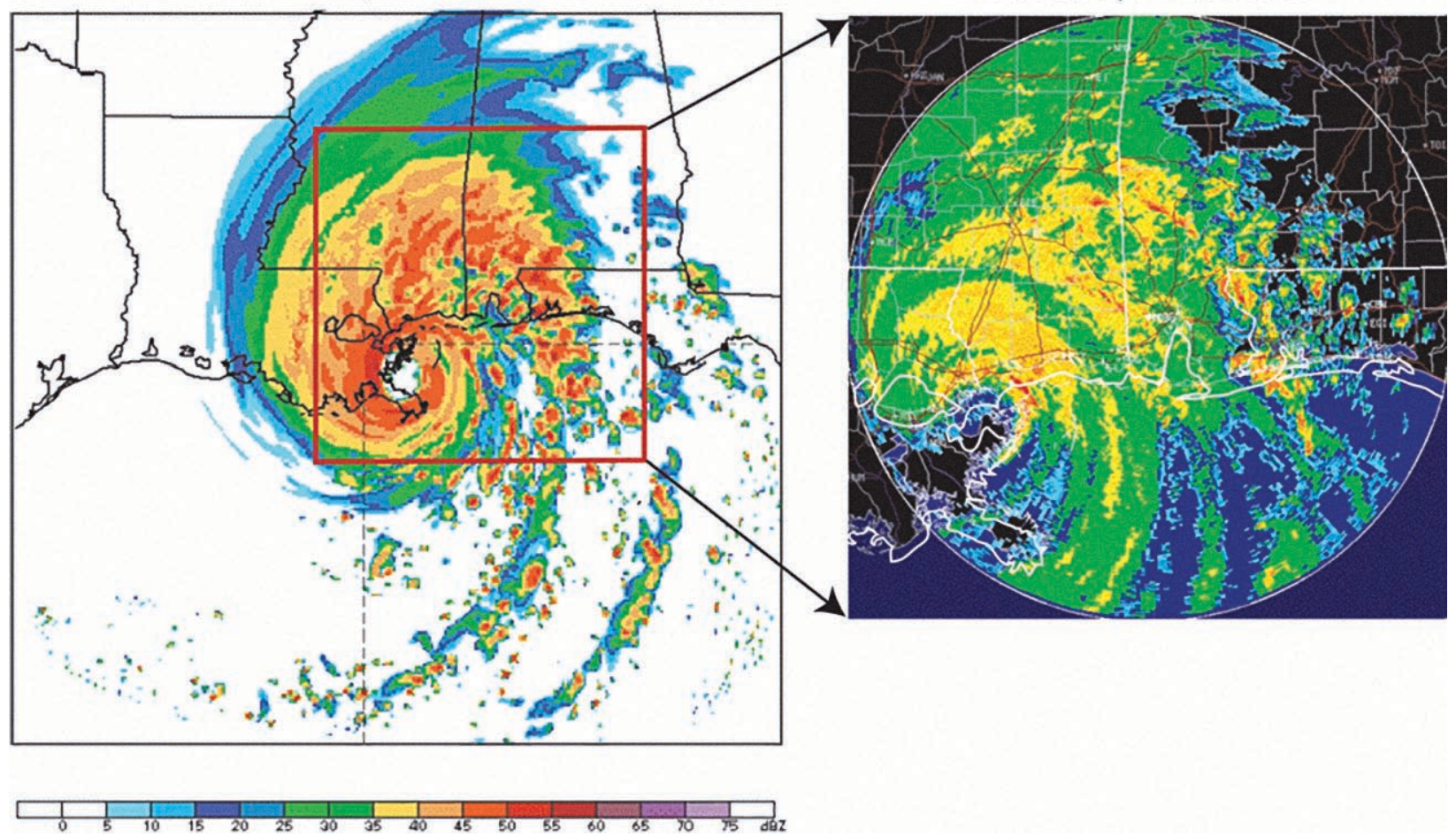

FIG. 6. The capability of high-resolution $(\sim \mathrm{km})$ regional forecast models to predict the intensity of high-impact weather events, such as the 29 Aug 2005 landfall of Hurricane Katrina over New Orleans, LA (Davis et al. 2008). (left) The NCAR WRF simulation of Hurricane Katrina precipitation radar reflectivity computed 3 days before landfall, compared with (right) radar observations of the actual landfall. Within the next decade, global data assimilation and deterministic and ensemble medium-range to seasonal prediction systems will advance to such high-resolution capabilities. 


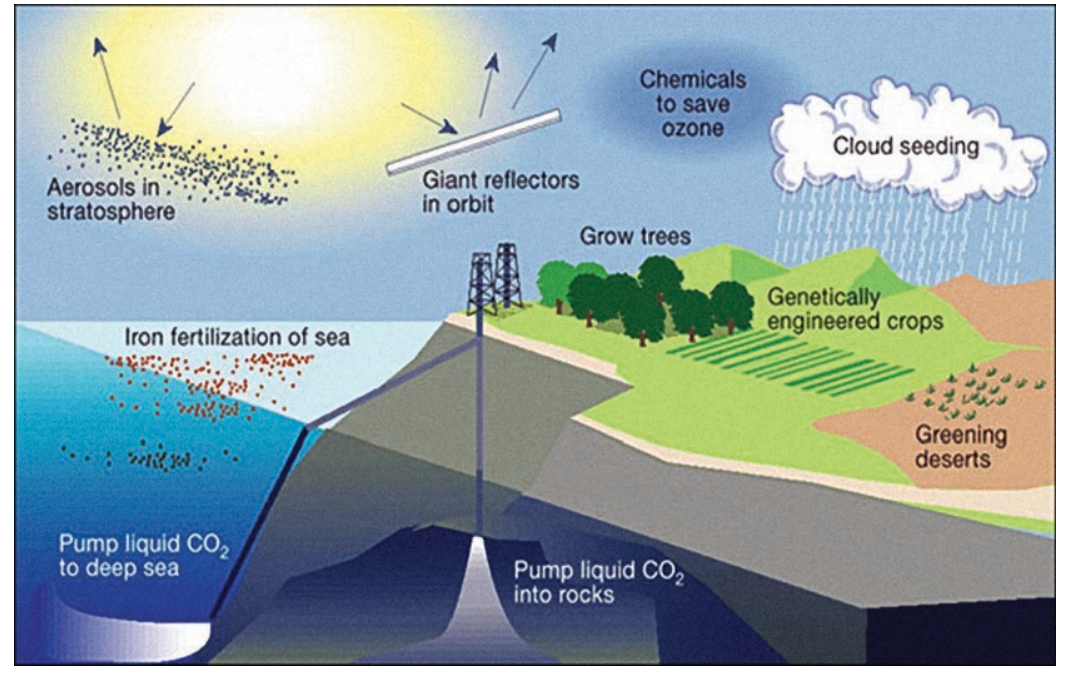

FIG. 7. Schematic representation of various climate-engineering

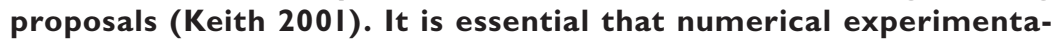
tion with high-resolution weather, climate, and complex Earth system models, with established fidelity and skill, provide scientifically based assessments of the global to regional impact of such engineering hypotheses prior to their design and implementation.

important for air quality (Fig. 8), UV radiation, and climate (Hollingsworth et al. 2008).

Studies to determine causes of past and current conditions. These conditions include extreme events, such as severe droughts, heat waves, and cyclones. Distinguishing between natural variability and human-forced, long-term trends is vital to inform both adaptation and mitigation decisions. Attribution studies, particularly with model ensembles, address the predictability of the system, the odds of anomalies and extremes, and the confidence that can be placed in the predictions.

Field experiments. Field experiments are used to evaluate and improve parameterizations and explicit representations of physical processes in weather and climate predictions systems, such as coupled land/ocean/sea ice boundary layer processes, precipitation, and radiative exchange. adaptation and mitigation. droughts, and floods. changing climate.
Information systems. These systems are for delivering timely, user-friendly, and issue-targeted input into decision-making for risk reduction, adaptation, mitigation, and sustainable development. This necessitates engagement with users of environmental information to assess and incorporate their requirements (ICSU 2008).

Archives. Archives are used as part of an internationally coordinated Earth information system (NRC 2003) to store and manage data and to enable access to operational and historical analyses and forecasts of weather; air quality; climate; and other Earth system components, including socioeconomic data required to develop risk models, commensurate with the highest resolution achievable. These archives should facilitate advanced analysis; reanalysis; reforecasts; and visualizations of observed and predicted events, including assessment of the effectiveness of mitigation and adaptation.

\section{HIGH-PERFORMANCE COMPUTING.}

HPC is crucial to accelerate advances in the previous elements and their applications. Advanced HPC

\section{DELIVERABLES OF THE EARTH PREDICTION INITIATIVE}

- Improved projections, predictions, and monitoring of multidecadal global to regional climate and coupled Earth system changes, including estimates of the frequency and intensity of regional extremes, their impacts and improved information on the assumptions, confidence, and uncertainty of all estimates.

- A stronger scientific foundation for developing and evaluating climate change

- Improved predictions of daily to interannual high-impact weather and climate, including winter storms, tropical cyclones, air quality, heat and cold waves,

- Improved early warning of famine, water shortages, pestilence, and disease in developing nations and the promotion of social and economic development in a

- Science-based information to develop and evaluate responses to weather; climate variability; change in sectors such as energy, water, agriculture, and health; and improved support for environmental and socioeconomic planning.

- Assessments of emerging geoengineering alternatives for controlling climate variability and change, including unintended consequences.

- Support for developing national and international climate services.

- Education and capacity building to enable the next generation of experts to carry out the vision and mission identified in this paper. 
will facilitate high-resolution data assimilation and analysis, as well as ensemble prediction systems that include many hundreds of possible predictions and projections. Models will be able to incorporate more realistic physical processes (e.g., clouds, precipitation) and a high degree of Earth system complexity, including two-way interactions between society and predicted responses. This will require dedicated computer facilities with sustained speeds well beyond the most advanced computers of today but which are achievable within the next 10-20 years. Realizing the full research and operational potential of HPC will require advanced data processing and visualization methods, user-friendly high-speed and broad-bandwidth communication, and common data formats. It will include training of scientists in the use of advanced computer systems and the integrated data distribution systems that facilitate access to most information in near-real time. It will also require advanced numerical methods and software to enable models to fully exploit the capacity of future supercomputers. It is critical for present and future national and international research centers to have access to sufficient computing capability and the scientific and technical resources to meet research and deliverable objectives on the scale envisioned (Shukla et al. 2009, 2010).

ADVOCACY AND COORDINATION. The proposed initiative requires champions to inform governments and other stakeholders of the urgency of supporting the effort, recognizing that such enterprises take years to succeed. In this vein, international organizations and agencies are beginning to coordinate activities that embrace components of EPI.

The WMO, sponsor of WWRP and the GAW air chemistry research program and cosponsor of GCOS and WCRP, will implement the concepts outlined in this article. In June 2008, the executive council of the WMO commissioned the Task Team on Research Aspects of an Enhanced Climate, Weather, Water and Environmental Prediction Framework (www. wmo.int/ecrtt). This team will develop a unified approach to multidisciplinary research and step up high-performance computing investments for coordinating and accelerating weather, climate, coupled chemical and hydrology model development, validation, and use. WWRP and WCRP are jointly coordinating these recommendations, which link global weather and climate research and prediction, consistent and supportive of the recommendations of the 2009 WMO WCC3 (www.wmo.wmo.int/wcc3) for establishment of a global framework for climate services. The EPI also engages ICSU through its cosponsorship of GCOS and WCRP and its academic constituency.

GEO is an international coordination framework across observations, analysis, prediction, information systems, and disciplines. It advocates for advancing climate, weather, water, and Earth system prediction. In implementing its 2009-11 Work Plan (www.grouponearthobservations.org/cdb/docshow. php? id=I), GEO is undertaking several tasks relevant to the EPI (e.g. Task CL-09-01: Environmental information for decision making, risk management, and adaptation).

THE GRAND CHALLENGE. The global scope required to realize accelerated advances in Earth system observation, analysis, and prediction capabilities is inescapable. All nations stand to benefit from its success. Unprecedented international collaboration and goodwill are necessary for the success of EPI. As nations, we have collaborated to advance global observing systems, weather forecasting, climate prediction, communication networks, and emergency preparedness and response. We must now extend this collaboration to embrace the full Earth system and the next frontier of socioeconomic and environmental applications of our science. Our community and supporting organizations are poised for the discoveries ahead and the opportunity to make our information available to users and decision makers to meet the needs of humanity. This is our grand challenge.

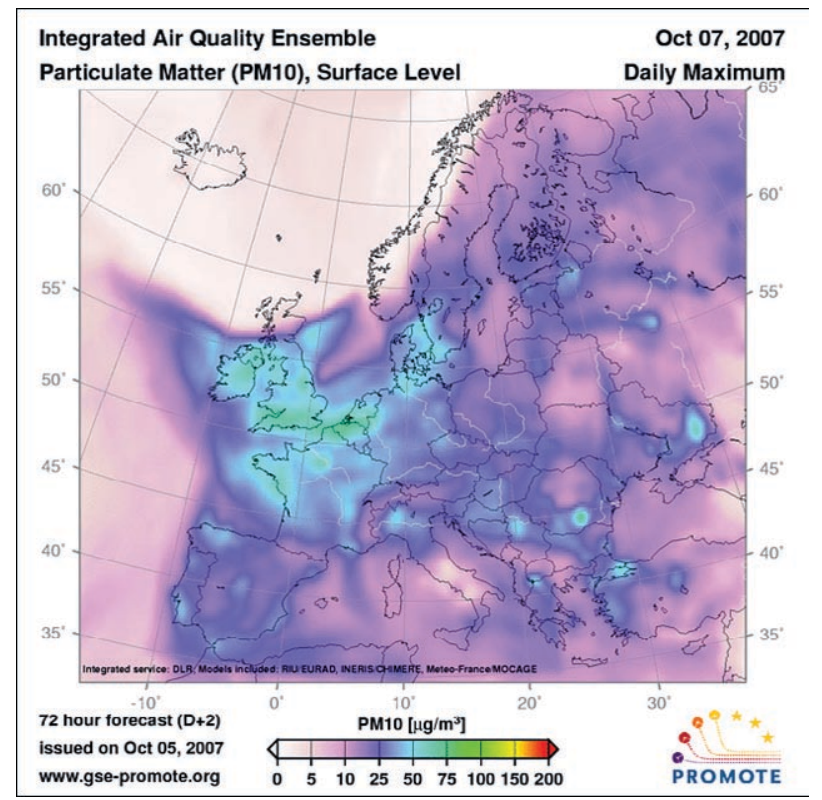

FIG. 8. 72-h ensemble air-pollutant forecast for European surface-level particulate matter (PMIO) for 7 Oct prepared by the DLR-DFD as part of GMES PROMOTE, funded by the European Space Agency. 


\section{APPENDIX: LIST OF ACRONYMS.}

CCSP

DLR-DFD

ECMWF

EPI

ESSP

EUMETSAT

GARP

GAW

GCOS

GEO

GEOSS

GEMS

GMES

HPC

ICSU

IGBP

IHDP

IOC

IPCC

IPY

ISSC

JAMSTEC

MERIT

MJO

MODIS

NAO

NCAR

NRC

NWP

PROMOTE

THORPEX

UCAR

UNEP

WCC3

WCRP

WHO

WMO

WWRP

WRF

YOTC

U.S. Climate Change Science Program

German Aerospace Research Establishment-German Remote Sensing Data Center

European Centre for Medium-Range Weather Forecasts

Earth-System Prediction Initiative

Earth System Science Partnership

European Organisation for the Exploitation of Meteorological Satellites

Global Atmospheric Research Programme

Global Atmospheric Watch

Global Climate Observing System

Group on Earth Observations

Global Earth Observation System of Systems

The Global and regional Earth-system (Atmosphere) Monitoring using Satellite and in situ data

Global Monitoring for Environmental Security

High-performance computing

International Council for Science

International Geosphere-Biosphere Programme

International Human Dimensions Programme on Global Environmental Change

Intergovernmental Oceanographic Commission

Intergovernmental Panel on Climate Change

International Polar Year

International Social Science Council

Japan Agency for Marine-Earth Science and Technology

Meningitis Environmental Risk Information Technologies

Madden-Julian oscillation

Moderate Resolution Imaging Spectroradiometer

North Atlantic Oscillation

National Center for Atmosphere Research

National Research Council

Numerical weather prediction

Protocol Monitoring for the GMES Service Element

The Observing System Research and Predictability Experiment

University Corporation for Atmospheric Research

United Nations Environment Programme

World Climate Conference 3

World Climate Research Programme

World Health Organization

World Meteorological Organization

World Weather Research Programme

Weather Research and Forecasting model

Year of Tropical Convection

\section{REFERENCES}

Angel, R., 2006: Feasibility of cooling the earth with a cloud of small spacecraft near the inner Lagrange-point (L1). Proc. Natl. Acad. Sci. USA, 103, 17 184-17 189.

Ballabrera-Poy, J., R. Murtugudde, R.-H. Zhang, and A. J. Busalacchi, 2007: Coupled ocean-atmosphere response to seasonal modulation of ocean color: Impact on interannual climate simulations in the tropical Pacific. J. Climate, 20, 353-374.
Brunet, G., and Coauthors, 2010: Collaboration of the weather and climate communities to advance subseasonal to seasonal prediction. Bull. Amer. Meteor. Soc., 91, 1397-1406.

Crutzen, P. J., 2006: Albedo enhancement by stratospheric sulfur injections: A contribution to resolve a policy dilemma? Climatic Change, 77, 211-219.

Davis, C., and Coauthors, 2008: Prediction of landfalling hurricanes with the advanced hurricane WRF model. Mon. Wea. Rev., 136, 1990-2005.

Dole, R. M., 2008: Linking weather and climate. 
Synoptic-Dynamic Meteorology and Weather Analysis and Forecasting, Meteor. Monogr., No. 55, Amer. Meteor. Soc., 297-348.

Döös, B. R., 2004: The First GARP global experimentA model of international cooperation. WMO Bull., 53, 199-206.

Erisman, J. W., M. A. Sutton, J. Galloway, Z. Klimont and W. Winiwarter, 2008: How a century of ammonia synthesis changed the world. Nat. Geosci., 1, 636-639.

Evan, A. T., J. Dunion, J. A. Foley, A. K. Heidinger, and C. S. Velden, 2006: New evidence for a relationship between Atlantic tropical cyclone activity and African dust outbreaks. Geophys. Res. Lett., 33, L19813, doi:10.1029/2006GL026408.

Hamill, T. M., J. Whitaker and S. Mullen, 2006: Reforecasts: An important dataset for improving weather predictions. Bull Amer. Meteor. Soc., 87, 33-46.

Hollingsworth, A., and Coauthors, 2008: Toward a monitoring and forecasting system for atmospheric composition: The GEMS project. Bull. Amer. Meteor. Soc., 89, 1147-1164.

Hurrell, J. W., G. A. Meehl, D. Bader, T. Delworth, B. Kirtman, and B. Wielicki, 2009: A unified modeling approach to climate system prediction. Bull. Amer. Meteor. Soc., 90, 1819-1832.

ICSU, 2008: A science plan for integrated research on disaster risk: Addressing the challenge of natural and human-induced environmental hazards. International Council for Science Planning Group on Natural and Human-Induced Environmental Hazards and Disasters Rep., 66 pp.

_- 2010: Regional Environmental Change: Human Action and Adaptation. ICSU Preliminary Rep., 28 pp. [Available online at www.icsu.org/2_resourcecentre/ICSU_Belmont_report/index.html.]

Jacob, D. J., and D. A. Winner, 2009: Effect of climate change on air quality. Atmos. Environ., 43, 51-63.

Karl, T. R., G. A. Meehl, C. D. Miller, S. J. Hassol, A. M. Waple, and W. L. Murray, Eds., 2008: Weather and climate extremes in a changing climate. Regions of focus: North America, Hawaii, Caribbean, and U.S. Pacific Islands. U.S. Climate Change Science Program and the Subcommittee on Global Change Research Synthesis and Assessment Product 3.3, $180 \mathrm{pp}$.

Kaufman, Y. J., D. Tanre, and O. Boucher, 2002: A satellite view of aerosols in the climate system. Nature, 419, 215-223.

Keith, D. W., 2001: Geoengineering. Nature, 409, 420.

Kelly-Hope, L., and M. Thompson, 2008: Climate and infectious diseases in seasonal forecasts. Climate Change and Human Health: Health and Climate,
M. Thomson, R. Garcia-Herra, and M. Beniston, Eds., Advances in Global Change Research, Vol. 30, Springer, 31-70.

Koren, I., Y. J. Kaufman, R. Washington, M. C. Todd, Y. Rudich, J. V. Martins, and D. Rosenfeld, 2006: The Bodélé depression: A single spot in the Sahara that provides most of the mineral dust to the Amazon. Environ. Res. Lett., 1, 014005, doi:10.1088/17489326/1/1/014005.

Latham, J. and Coauthors, 2008: Global temperature stabilization via controlled albedo enhancement of low-level maritime clouds. Philos. Trans. Roy. Soc. London, 366A, 3969-3987.

Leemans, R., and Coauthors, 2009: Developing a common strategy for integrative global environmental change research and outreach: The Earth System Science Partnership (ESSP). Curr. Opin. Environ. Sustainability, 1, 4-13, doi:10.1016/j. cosust.2009.07.013.

Li, F., A. M. Vogelmann, and V. Ramanathan, 2004: Saharan dust aerosol radiative forcing measured from space. J. Climate, 17, 2558-2571.

Meehl, G. A., and Coauthors, 2007: Global climate projections. Climate Change 2007: The Physical Science Basis, S. Solomon et al., Eds., Cambridge University Press, 747-845.

— - and Coauthors, 2009: Decadal prediction: Can it be skillful? Bull. Amer. Meteor. Soc., 90, 1467-1485.

Moncrieff, M. W., M. Shapiro, J. Slingo, and F. Molteni, 2007: Collaborative research at the intersection of weather and climate. WMO Bull., 56, 204-211.

Murtugudde, R., J. Beauchamp, and A. Busalacchi, 2002: Effects of penetrative radiation on the upper tropical ocean circulation. J. Climate, 15, 470-486.

Nobre, C., and Coauthors, 2010: Addressing the complexity of the earth system. Bull Amer. Meteor. Soc., 91, 1389-1396.

NRC, 2003: Satellite Observations of the Earth's Environment: Accelerating the Transition of Research to Operations. National Academies Press, 163 pp.

_- 2007: Earth Science and Applications from Space: National Imperatives for the Next Decade and Beyond. National Academies Press, 428 pp.

—, 2008: Earth Observations from Space: The First 50 years of Scientific Achievements. National Academies Press, 129 pp.

Palmer, T. N., F. J. Doblas-Reyes, A. Weisheimer, and M. J. Rodwell, 2008: Toward seamless prediction: Calibration of climate change projections using seasonal forecasts. Bull. Amer. Meteor. Soc., 89, 459-470.

Robock, A., 2008: 20 reasons why geoengineering may be a bad idea. Bull. At. Sci., 64, 14-18. 
Rysgaard, S., J. Bendtsen, L. T. Pedersen, H. Ramlov, and R. N. Glud, 2009: Increased $\mathrm{CO}_{2}$ uptake due to sea ice growth and decay in the Nordic Seas. J. Geophys. Res., 114, C09011, doi:10.1029/2008JC005088.

Schepanski, K., I. Tegen, B. Laurent, B. Heinold, and A. Macke, 2007: A new Saharan dust source activation frequency map derived from MSG-SEVIRI IR-channels. Geophys. Res. Lett., 34, L18803, doi:10.1029/2007GL030168.

Shapiro, M., and Coauthors, 2007: The socio-economic and environmental benefits of a revolution in weather, climate and Earth system analysis and prediction. The Full Picture, Group on Earth Observation, 136-138.

Shukla, J., R. Hagedorn, B. Hoskins, J. Kinter, J. Marotzke, M. Miller, T. N. Palmer, and J. Slingo, 2009: Revolution in climate prediction is both necessary and possible: A declaration at the World Modelling Summit for Climate Prediction. Bull. Amer. Meteor. Soc., 90, 175-178.

_ T. N. Palmer, R. Hagedorn, B. Hoskins, J. Kinter, J. Marotzke, M. Miller, and J. Slingo, 2010: Toward a new generation of world climate research and computing facilities. Bull. Amer. Meteor. Soc., 91, 1407-1412.

Simmons, A. J., and A. Hollingsworth, 2002: Some aspects of the improvement in skill of numerical weather prediction. Quart. J. Roy. Meteor. Soc., 128, 647-677.

Todd, M. C., R. Washington, S. Raghavan, G. Lizcano, and P. Knippertz, 2008: Regional model simulations of the Bodélé low-level jet of northern Chad during the Bodélé Dust Experiment (BoDEx 2005). J. Climate, 21, 995-1012.

Trenberth, K. E., 2008: Observational needs for climate prediction and adaptation. WMO Bull., 57, $17-21$.

Uppala, S., A. J. Simmons, and P. Källberg, 2004: Global numerical weather prediction: An outcome of FGGE and a quantum leap for meteorology. WMO Bull., 53, 207-212.

Walter, V. R., C. Bréchignac, and Y. T. Lee, 2009: Earth system research priorities. Science, 325, 245.

Yoshioka, M., N. M. Mahowald, A. J. Conley, W. D. Collins, D. W. Fillmore, C. S. Zender, and D. B. Coleman, 2007: Impact of desert dust radiative forcing on Sahel precipitation: Relative importance of dust compared to sea surface temperature variations, vegetation changes, and greenhouse gas warming. J. Climate, 20, 1445-1467. 